Table 1. Cardiovascular risk factors at baseline and after one year

\begin{tabular}{|c|c|c|}
\hline & Baseline & Follow-up \\
\hline CV disease history & $20(7.5)$ & $23(8.6)$ \\
\hline CV risk $<10 \%$ & $43(16.2)$ & $52(19.5)^{\star}$ \\
\hline CV risk $10-20 \%$ & $60(22.6)$ & $62(23.3)$ \\
\hline CV risk > 20\% & $143(53.8)$ & $129(48.5)^{\star}$ \\
\hline $\mathrm{SBP}$ in $\mathrm{mm} / \mathrm{Hg}$ & $135 \pm 17$ & $135 \pm 18$ \\
\hline Body Mass Index in $\mathrm{kg} / \mathrm{m}^{2}$ & $26.4 \pm 5.0$ & $26.3 \pm 4.8$ \\
\hline $\mathrm{TC}$ in $\mathrm{mmol} / \mathrm{l}$ & $5.5 \pm 1.0$ & $5.2 \pm 1.0^{\star \star}$ \\
\hline Triglycerides in $\mathrm{mmol} / \mathrm{l}$ & $1.4 \pm 0.8$ & $1.4 \pm 0.8$ \\
\hline LDL-cholesterol in $\mathrm{mmol} / \mathrm{l}$ & $3.2 \pm 0.9$ & $3.0 \pm 0.9^{\star \star}$ \\
\hline $\mathrm{HDL}$-cholesterol in $\mathrm{mmol} / \mathrm{l}$ & $1.6 \pm 0.5$ & $1.6 \pm 0.5$ \\
\hline TC/HDL-ratio & $3.7 \pm 1.2$ & $3.7 \pm 1.2^{\star *}$ \\
\hline Current smokers & $60(22.6)$ & $53(20.1)$ \\
\hline Diabetes mellitus & $12(4.5)$ & $12(4.5)$ \\
\hline $\mathrm{SBP}>140 \mathrm{~mm} / \mathrm{Hg}$ & $95(35.7)$ & $96(36.2)$ \\
\hline $\mathrm{LDL}>2,5 \mathrm{mmol} / \mathrm{l}$ & $208(78.8)$ & $180(68.4)^{\star \star}$ \\
\hline $\mathrm{TC} \geq 6.5 \mathrm{mmol} / \mathrm{l}$ & 37 (13.9) & $26(9.8)$ \\
\hline Antihypertensives & $81(30.5)$ & $88(33.1)$ \\
\hline Statins & $38(14.3)$ & $57(21.4)^{\star \star}$ \\
\hline
\end{tabular}

$\mathrm{CV}=$ Cardiovascular, $\mathrm{HDL}=$ high-density lipoprotein, $\mathrm{LDL}=$ low-density lipoprotein, $\mathrm{TC}=$ total cholesterol, SBP $=$ Systolic blood pressure. Results are presented as mean \pm standard deviation or $\mathrm{n},(\%) .{ }^{*} \mathrm{p}<0.05,{ }^{* *} \mathrm{p}<0.01$

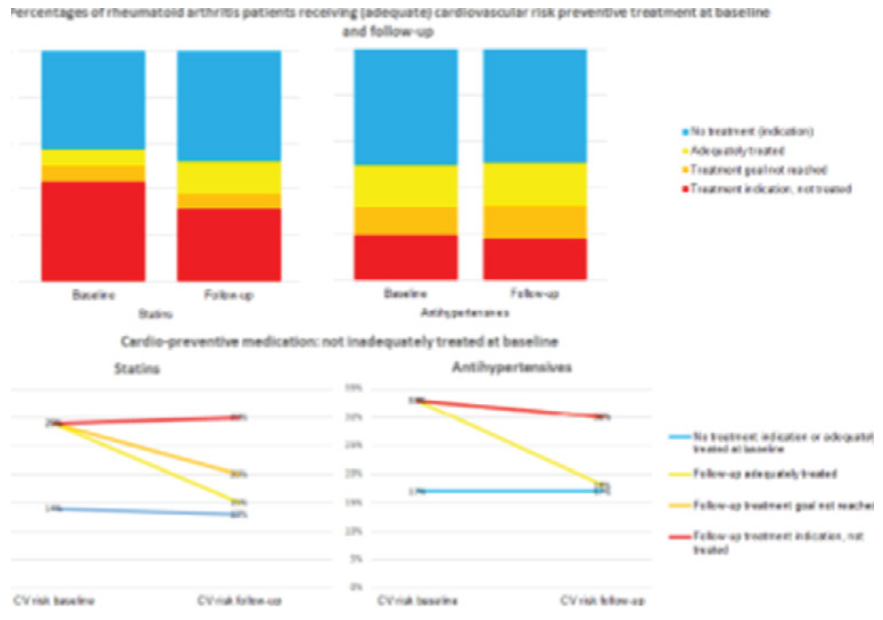

management program, only $14,3 \%$ patients with an indication for preventive treatment visited their GP and only $14 \%$ started with CV risk lowering drugs. This is mainly caused by the small percentage of high risk patients that contacted their GP. On the other hand, a high percentage reported the start of healthy lifestyle. These results underscore the need for a short-term follow-up, in close collaboration with primary care providers to ensure appropriate CV risk management. This is a future implementation project that will be initiated shortly.

References:

[1] Ann Rheum Dis 2015;74:192.

Disclosure of Interest: None declared

DOI: 10.1136/annrheumdis-2017-eular.3188

\section{SAT0115 EFFECT OF BIOLOGICAL DISEASE MODIFYING ANTI-RHEUMATIC DRUGS (BDMARDS) ON CARDIO VASCULAR DISEASE (CVD) RISK IN RA PATIENTS:THREE YEARS RESULTS FROM A CANADIAN COHORT}

M. Khraishi ${ }^{1}$, C. Molta ${ }^{2}$, A. Lewis ${ }^{3} .{ }^{1}$ Rheumatology, Memorial University of Newfoundland, St. John's, Canada; ${ }^{2}$ Rheumatology, MainLine Rheumatology Lankenau Medical Center, Philadelphia, United States; ${ }^{3}$ Epidemiology, Memorial University of Newfoundland, St. John's, Canada

Background: RA patients have a higher risk for developing CV Diseases (e.g. IHD and stroke) than the general population. We reported previously (ACR, EULAR) the results $\mathrm{CV}$ risk in our patients treated with bDMARDs for $1 \& 2$ years.

Objectives: To assess the effect of bDMARDs treatment on 10-year CV disease risk in patients with RA after 36 months and evaluate the impact of their use on the incidence of $\mathrm{CV}$ events

Methods: A cohort of RA patients was followed prospectively.Demographics, disease activity parameters, inflammatory markers, CV events, CVD 10 year risk assessment [Framingham Risk Score (FRS)] were ascertained at the baseline and every six months, up to 36 months. Statistical analysis utilized SPSS (IBM version 24) software.

Results: 321 patients were included, of those 270 patients were followed for three years. Eight BDMARDs were included evaluating their effect on disease activity and $C V$ risk in 233 patients who continued on their prospective biologic for the three years.

Significant overall reduction in disease activity in all groups was obtained as compared to baseline. The whole group DAS improved from 3.996 to 3.118.
The HAQ also improved significantly (1.201 to 0.857$)$ and the CRP improved significantly (12.91 $\mathrm{mg} / \mathrm{L}$ to 7.3$)$.

Overall, Total cholesterol (TC) changed from $5.195 \mathrm{mmol} / \mathrm{L}$ at baseline to 4.992 (P 0.001). High Density Lipoprotein Cholesterol (HDL-C) increased significantly at 36 months from 1.336 to 1.376. However, the Atherogenic Index (AI) for the whole cohort changed from 3.636 to 3.845 . The overall 10 year risk of cardiovascular event increased from 12.878 to 13.8

The cohort included 321 patients. Eight bDMARDs were evaluated to assess their effect on disease activity and CVD risk. The outcomes in 233 patients who continued their prospective biologic for the three years were reported (table). $77 \%$ were females, median RA duration was 11 ys. Significant reduction in disease activity in all groups was achieved vs. baseline. The DAS improved from 3.996 to 3.118 , the HAQ improved significantly (1.201 to 0.857 ) and the CRP also improved significantly (12.91 $\mathrm{mg} / \mathrm{L}$ to 7.3$)$. Overall, Total cholesterol (TC) changed from $5.195 \mathrm{mmol} / \mathrm{L}$ at baseline to 4.992 (P 0.001). High Density Lipoprotein Cholesterol (HDL-C) increased significantly at 36 months from 1.336 to 1.376 . The Atherogenic Index (Al) for the cohort changed from 3.636 to 3.845 . The overall 10 year risk of cardiovascular event increased from12.878 to 13.8 .

Table 1

\begin{tabular}{lcccccc}
\hline & $\begin{array}{c}\text { Rituximab } \\
\mathrm{n}=40\end{array}$ & $\begin{array}{c}\text { Tocilizumab } \\
\mathrm{n}=42\end{array}$ & $\begin{array}{c}\text { Golimumab } \\
\mathrm{n}=24\end{array}$ & $\begin{array}{c}\text { Adalimumab } \\
\mathrm{n}=42\end{array}$ & $\begin{array}{c}\text { Abatacept } \\
\mathrm{n}=35\end{array}$ & $\begin{array}{c}\text { Etanercept } \\
\mathrm{n}=39\end{array}$ \\
\hline DAS 28 & 4.3 vs 3.7 & 4.2 vs 2.8 & 4.1 vs 3.4 & 3.4 vs 2.8 & 4.3 vs 3.1 & 4.0 vs 2.8 \\
& $\mathrm{P} 0.014$ & $\mathrm{P}<0.001$ & $\mathrm{P} 0.028$ & $\mathrm{P} 0.011$ & $\mathrm{P}<0.001$ & $\mathrm{P} 0.0015$ \\
$\mathrm{HAQ}$ & 1.3 vs 1.1 & 1.0 vs 0.9 & 1.2 vs 1.0 & 1.7 vs 0.5 & 1.2 vs 1.0 & 1.1 vs 0.7 \\
& & & & & & $\mathrm{P}<0.001$ \\
Swollen Joint & 3.8 vs 2.1 & 5.0 vs 1.8 & 5.3 vs 6.7 & 3.6 vs 1.7 & 3.7 vs 3.6 & 3.9 vs 1.7 \\
Count & $\mathrm{P} 0.005$ & $\mathrm{P}<0.001$ & & $\mathrm{P} 0.010$ & & $\mathrm{P}<0.001$ \\
Al & 4.0 vs 3.7 & 4.7 vs 4.0 & 3.2 vs 3.94 & 3.8 vs 3.7 & 4.1 vs 3.9 & 4.2 vs 3.7 \\
& $\mathrm{P} 0.045$ & & & & &
\end{tabular}

10 yr CV Risk 15.9 vs $17.9 \quad 13.5$ vs $14.4 \quad 14$ vs $15.7 \quad 10.1$ vs $13.2 \quad 13.5$ vs 14.111 .2 vs 12.2 P 0.009

Conclusions: The bDMARDS studied were effective in controlling the disease activity of RA. Although the overall CVD risk was not reduced in the group as a whole at 36 months, bDMARDS may still play a role in reducing the CVD risk in these patients

Disclosure of Interest: M. Khraishi Grant/research support from: Roche Canada, C. Molta: None declared, A. Lewis: None declared

DOI: 10.1136/annrheumdis-2017-eular.1436

\section{SAT0116 PREVALENCE OF UNACCEPTABLE PAIN IN PATIENTS WITH LONG-STANDING RA}

M.L. Andersson, K. Forslind, B. Svensson. Department of Clinical Sciences, Section of Rheumatology, Lund University, Lund and Helsingborg, Sweden

Background: Pain in patients with rheumatoid arthritis (RA) is the most common and troublesome symptom, occurs frequently in many sites in the muscularskeletal system, causes fatigue and functional impairment. The origin of pain in RA may be inflammatory and/or other, such as increased sensitivity to pain, fibromyalgia and osteoarthritis.

Objectives: To study unacceptable pain in an inception cohort of patients with RA at 15 years follow-up

Methods: This study concerns 477 patients from the BARFOT inception cohort study, consisting of 839 patients with early RA, who have passed the pre-defined 15 year follow-up visit. Unacceptable pain (UP) was defined as $>40 \mathrm{~mm}$ on a continuous VAS pain scale of $100 \mathrm{~mm}$ with the ends "no pain" and "worst possible pain" (1). ADL- function was assessed by the HAQ test, physical function by the SOFI test and joint damage by the van der Heijde modified Sharp method. Remission was defined as DAS28 $\leq 2.6$.

The prevalence of UP over time as well as the relationship of UP with clinical variables were assessed. Baseline predictors of UP after 15 years were evaluated by logistic regression.

Results: The mean baseline VAS pain was $45 \mathrm{~mm}$, decreased after 6 months to 29 and remained after that fairly stable through the years ending in 31 at 15 years. UP followed a similar course with $56 \%$ of the patients at baseline, which decreased to $30 \%$ after 6 months and then behaved stable until 15 years, $34 \%$ Seventy-seven per cent of the patients with UP were not in remission at 15 years, while $23 \%$ had UP in spite of being in remission.

Patients with UP who were in remission at the 15 years visit had higher mean age $(p=0.004)$, ESR $(p=0.001)$ and SOFI $(p=0.001)$ than patients without UP.

Patients with UP who were not in remission at this point in time were more often women $(0.008)$ and had more tender joints $(p=0.001)$ than patients who did not have UP.

In both remission groups the mean DAS28, patient global assessment and HAQ were higher in patients with UP compared with patients without.

The means of the $x$-ray joint damage scores - total score, erosion and joint space narrowing scores - were very similar among patients with or without UP, statistically not significant.

A logistic regression analysis of the ability of baseline variables to predict UP at 15 years was performed. It was shown that female gender and baseline pain independently predicted unacceptable pain at 15 years in patients not in remission while in patients in remission high age and ESR were independent predictors. 